Article

\title{
Selection of C-Type Filters for Reactive Power Compensation and Filtration of Higher Harmonics Injected into the Transmission System by Arc Furnaces
}

\author{
Andrzej Grzegorz Lange ${ }^{1}$ and Grzegorz Redlarski ${ }^{2, *(1)}$ \\ 1 Department of Electrical, Power, Electronic and Control Engineering, University of Warmia and Mazury in \\ Olsztyn, 10-719 Olsztyn, Poland; andrzej.lange@uwm.edu.pl \\ 2 Department of Mechatronics and High Voltage Engineering, Faculty of Electrical and Control Engineering, \\ Gdansk University of Technology, 80-233 Gdańsk, Poland \\ * Correspondence: grzegorz.redlarski@pg.edu.pl
}

Received: 31 March 2020; Accepted: 5 May 2020; Published: 7 May 2020

\begin{abstract}
This article presents a method for selecting the elements of a C-type filter working with a conventional LC-type filter for compensating reactive power and filtering out higher harmonics generated by arc furnaces and ladle furnaces. The study was conducted in a steel mill supplied by a $110 \mathrm{kV}$ transmission system, where higher harmonic currents and nonlinear loads were measured. A series of computer simulations were performed under various operating conditions, and an algorithm for selecting the parameters of a third-order C-type filter (for suppressing the second harmonic) and two second-order LC-type filters (for suppressing the third harmonic) was proposed. The filtering system was tested in an arc furnace with the highest rated power, and harmonics in the current spectrum were evaluated. The results of the measurements were used to analyze the effectiveness of the compensation system comprising two passive C-type and LC-type filters at different system configurations. C-type filters significantly influenced current harmonics. The influence of the changes in the number of arc furnace transformers on the true Root Mean Square (RMS) of the currents injected into the $110 \mathrm{kV}$ transmission system and on the voltages of the $110 \mathrm{kV}$ busbars was discussed.
\end{abstract}

Keywords: power quality; reactive power control; power harmonic filters; harmonic analysis

\section{Introduction}

The growing use of electronic systems in power receivers decreases energy consumption in numerous production processes [1-4], but also creates new risks. The associated dangers include higher harmonic components that lead to the unnecessary activation of protective devices, such as residual-current protection devices [5-7], harmonic components that disrupt the operation of automatic synchronizers [8], as well as harmonic components that occur in non-stationary signals in various interdisciplinary applications, for example related to acoustics [9], electric vehicles [10], or even seemingly distant biomedical engineering [11,12].

Arc furnaces and ladle furnaces are the largest power receivers in steel mills. They operate with low power factors [13-18] and inject higher harmonic currents into the transmission system. Due to the operating characteristics of an electric arc between two carbon electrodes, the current is asymmetrical relative to ordinates and abscissas, which produces odd (third, fifth, seventh, etc.) as well as even (second, fourth, sixth, etc.) harmonics in the current spectrum [16-19]. Even and odd harmonic currents have to be reduced in industrial plants [20]. Industrial furnaces are high-power systems that require 
LC-type passive filters for compensating the reactive power of the first harmonic and for filtering out higher harmonics. A compensation system should be equipped with a C-type filter to reduce second harmonic generation. In most studies dedicated to the selection of C-type filters, the presence of other filters in the system is disregarded, and the proposed selection methods are narrowed down to C-type filters and the impedance of the transmission system [21,22]. The second harmonic current can be increased when the presence of LC-type filters is disregarded during the design of a C-type filter for reducing out the second harmonic current or when third harmonic filters are installed without a second harmonic filter. It is worth noting that active filters can be used for reactive power compensation and filtration of higher harmonics, but due to the very high power of arc furnaces and the high cost of active filters it is usually unreasonable and therefore passive filters or less often hybrid filters are used [23-25]. Static Var Compensator (SVC) systems are also applied to compensate arc furnaces [26-28].

Various algorithms for selecting C-type filters have been proposed in the literature [29-34]. However, the developed algorithms were verified mainly during computer simulations, and the selected parameters have never been tested in a real-world setting. The operation of an electric arc furnace is a dynamic process, and computer simulations do not always accurately predict the behavior of a compensation system in a steel mill. Computer simulations do not always account for the system's operation in different configurations, including with/without a C-type filter in systems equipped with an LC-type filter, or the system's response to changes in the operating parameters of an arc furnace. A compensation system has been designed and tested in a real-world setting in only one study [35]. However, the choice of resistance parameter, $R_{\mathrm{T}}$, which is the most important step during the selection of C-type filters, was not discussed.

\section{Specification of the Transmission System}

LC-type passive filters can have different topologies, which are presented in Figure 1. The filter selection algorithm for a system with arc furnaces was tested in an industrial plant whose power supply system is presented in Figure 2a, and the supply system parameters are described in Table 1. Third and higher harmonics $(3,4,5$, etc.) are usually reduced with second-order LC-type filters (Figure 2b,c). Due to the proximity of the second and first harmonics, a third-order C-type filter is generally applied to limit the second harmonic. The quality of electric power was measured in the plant's substation in the transformer field at $110 \mathrm{kV}$. Measurement results are discussed in Section 5 for the different transformers.

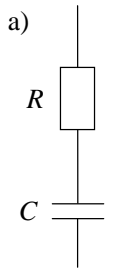

d)

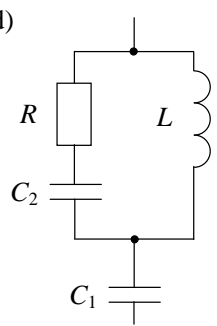

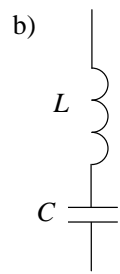

c)

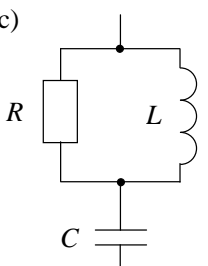

e)

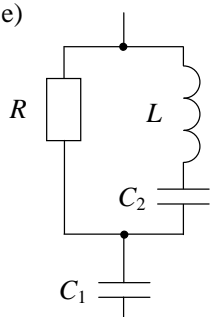

Figure 1. Types of filters used in the HV networks according to EN 61642 [36]. (a) First-order filter. (b) Second-order filter-undamped filter. (c) Second-order filter-damped filter with a resistor. (d) Third-order filter-damped filter. (e) Third-order filter-C-type filter. 


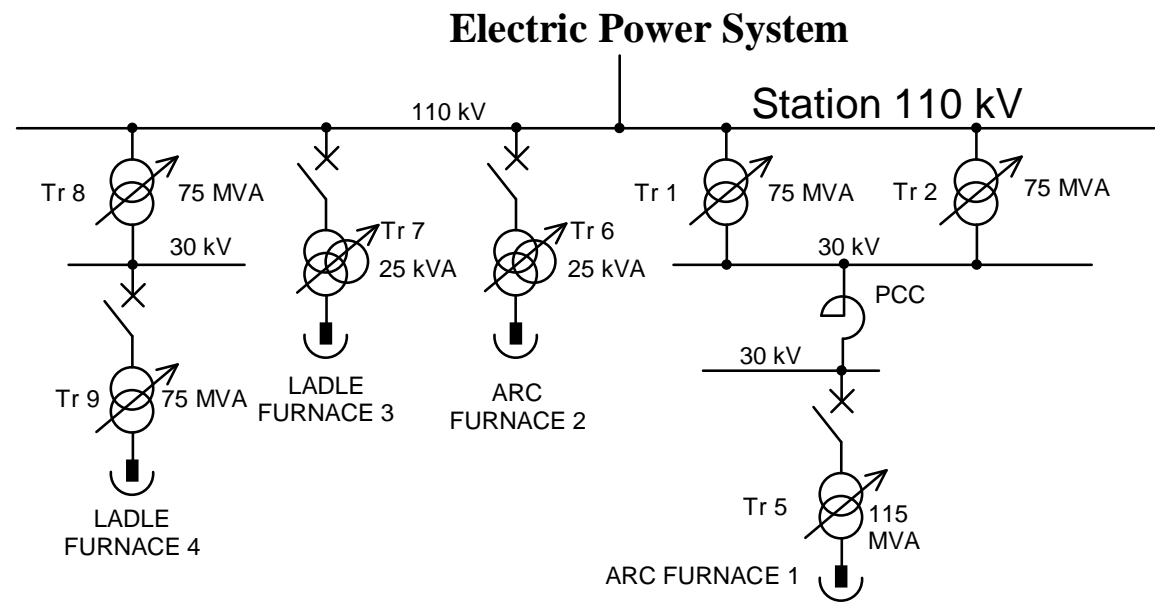

(a)

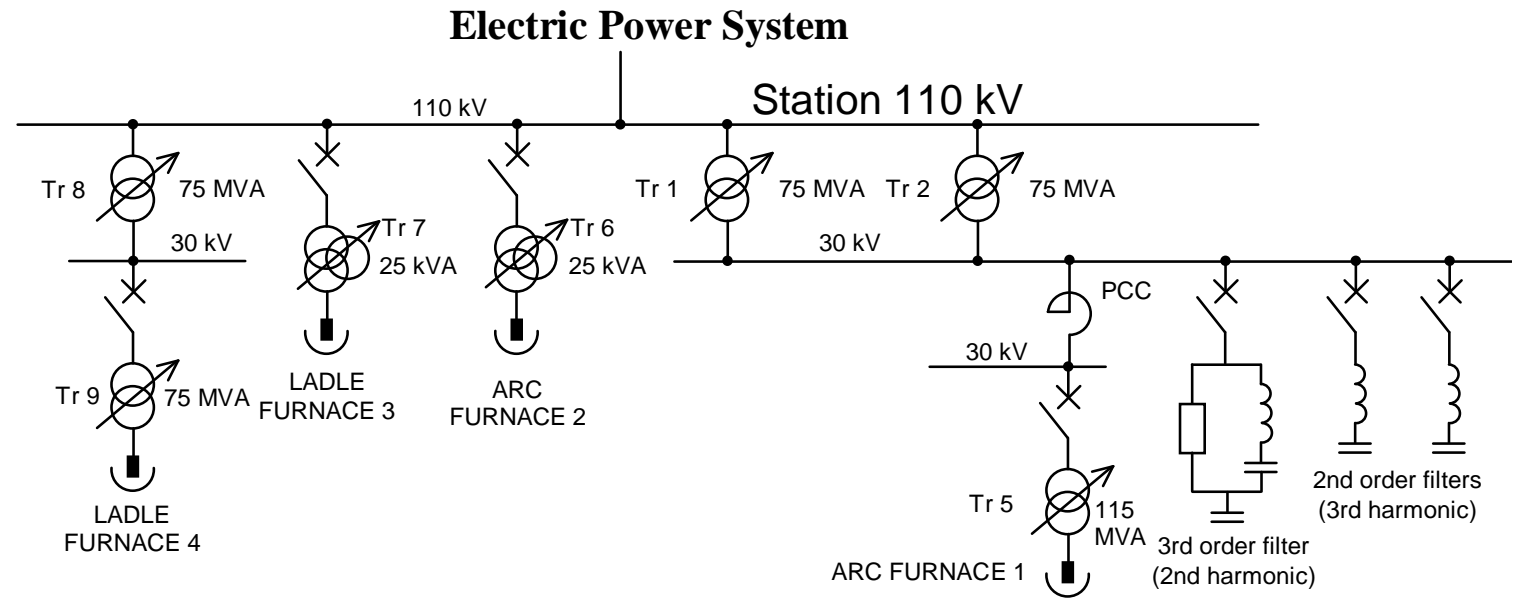

(b)

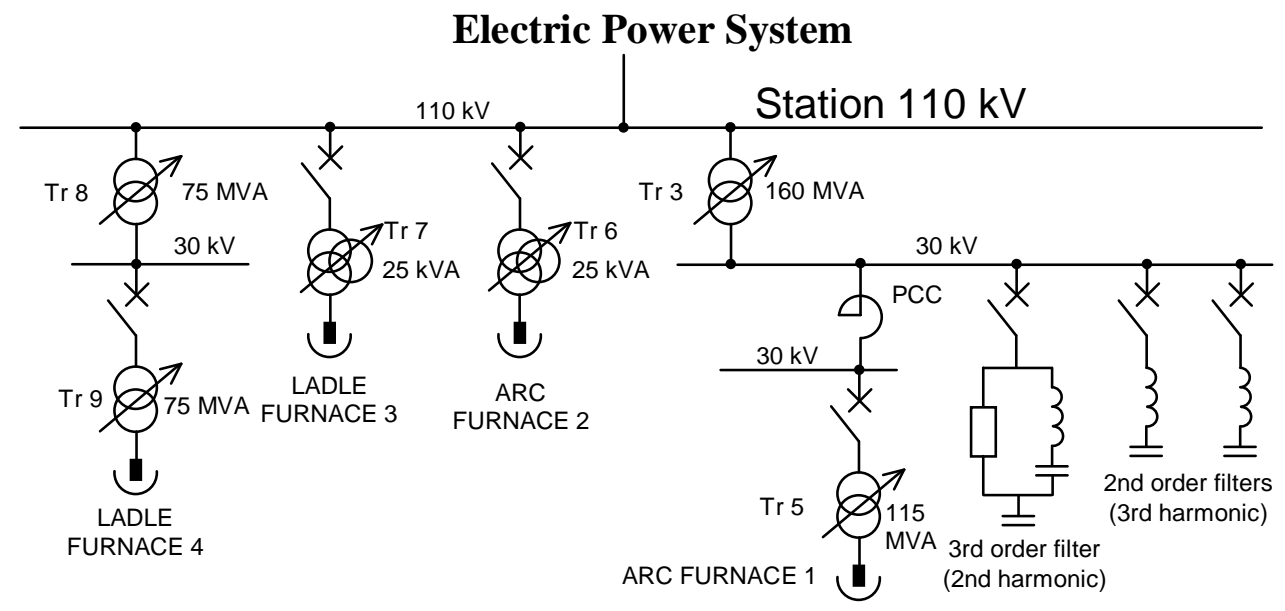

(c)

Figure 2. The analyzed electric power system configurations. (a) Diagram of the transmission system. (b) Diagram of a transmission system with reactive power compensation where higher harmonics are filtered by LC-type and C-type filters when arc furnace 1 is supplied by transformers $\operatorname{Tr} 1$ and $\operatorname{Tr} 2$. (c) Diagram of a transmission system with reactive power compensation where higher harmonics are filtered by LC-type and C-type filters when arc furnace 1 is supplied by transformer $\operatorname{Tr} 3$. 
Table 1. Parameters of the transmission system and the transformer.

\begin{tabular}{ccc}
\hline Type & Parameter & Value \\
\hline \multirow{3}{*}{ System } & Higher voltage rating $U_{\mathrm{GN}}$ & $110 \mathrm{kV}$ \\
& Breaking capacity $S_{\mathrm{Z}}$ & $1513 \mathrm{MVA}$ \\
& Lower voltage rating $U_{\mathrm{DN}}$ & $30 \mathrm{kV}$ \\
& System reactance $X_{\mathrm{S}}(\mathrm{GN})$ & $8.7971 \Omega$ \\
\hline \multirow{2}{*}{ T1 and T2 transformer } & Power rating $S_{\mathrm{N}}$ & $75 \mathrm{MVA}$ \\
& Percentage impedance/percentage & $7.63 \%$ \\
& short-circuit voltage $U_{\mathrm{Z}} \%$ & $110 \mathrm{kV}$ \\
& Higher voltage rating $U_{\mathrm{GN}}$ & $30 \mathrm{kV}$ \\
& Lower voltage rating $U_{\mathrm{DN}}$ & $0.7883 \Omega$ \\
\hline & Transformer reactance $X_{\mathrm{T}}(\mathrm{DN})$ & $160 \mathrm{MVA}$ \\
& Power rating $S_{\mathrm{N}}$ & $16.49 \%$ \\
& Percentage impedance $/$ percentage & $115 \mathrm{kV}$ \\
& short-circuit voltage $U_{\mathrm{Z}} \%$ & $31.5 \mathrm{kV}$ \\
& Higher voltage rating $U_{\mathrm{GN}}$ & $0.8893 \Omega$ \\
\hline
\end{tabular}

\section{Theoretical Analysis}

Reactive power consumption was calculated at $60 \mathrm{MVAr}$, based on the measurements of reactive power of the first harmonic. A 20 MVAr third-order C-type filter was used first due to the presence of the second harmonic, and the remaining harmonics were filtered out with two identical $20 \mathrm{MVAr}$ second-order LC-type filters. The LC-type filter should be selected first, and the third-order C-type filter should be chosen accordingly.

\subsection{Selection of an LC-Type Filter}

The effectiveness of an LC-type filter is determined mainly by the self-resonant frequency (Figure 3), which is defined by the following formula:

$$
n_{\mathrm{r}}=\sqrt{\frac{X_{\mathrm{C}}}{X_{\mathrm{DO}}}}
$$

where $X_{C}$-represents the capacitive reactance of the bank for the first harmonic; and $X_{\mathrm{DO}}$-the inductive reactance of the choke for the first harmonic.

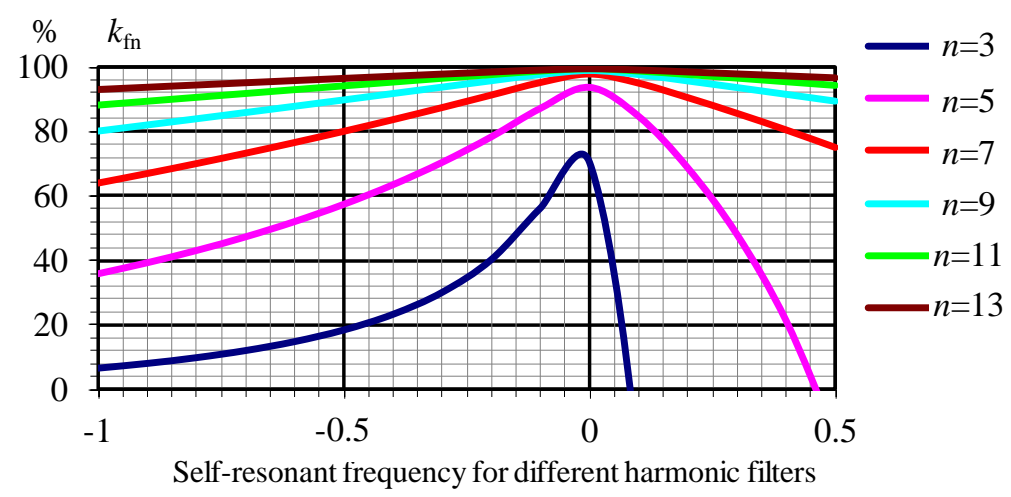

Figure 3. Filtering out higher harmonics as a function of the departure of the self-resonant frequency from the order of the filtered harmonic, subject to the self-resonant frequency of the applied filter $\left(n-n_{\mathrm{r}}\right)$. 
The suppression of the $n$th harmonic in the system was defined as

$$
k_{\mathrm{fn}}=\frac{U_{n f}^{\prime}}{U_{n \mathrm{f}}^{\prime \prime}}
$$

where $U_{n \mathrm{f}}^{\prime}$-phase voltage of the $n$th harmonic after compensation with $k$ capacitor units, in $\mathrm{V}$; and $U_{n f}^{\prime \prime}$ - phase voltage of the $n$th harmonic before compensation, in V.

Coefficient $k_{\mathrm{fn}}$ denotes the degree to which the harmonic component of the supply voltage is reduced by the compensation system or a passive filter. A given harmonic is suppressed when coefficient $k_{\mathrm{f} n}$ is less than 1 , and it is enhanced when coefficient $k_{\mathrm{f} n}$ is greater than 1 . The below formula can be used to express coefficient $k_{\mathrm{f} n}$ in percentage terms:

$$
k_{\mathrm{f} n \%}=\left(1-k_{\mathrm{f} n}\right) \cdot 100 \%=\left(1-\frac{U_{n}^{\prime}}{U_{n}^{\prime \prime}}\right) \cdot 100 \%
$$

The percent filtration (enhancement) coefficient can have positive or negative values. A positive value ("+") denotes the percent suppression of a given harmonic, whereas a negative value (" -") denotes the percent enhancement of a given harmonic.

Suppression efficiency is also determined by the $Q_{\mathrm{DO}}$-factor of the choke applied in the system with an LC-type filter (Figure 4). The goodness-of-fit of a filter choke is determined as follows:

$$
Q_{\mathrm{DO}}=\frac{X_{\mathrm{DO}}}{R_{\mathrm{DO}}}
$$

where $X_{\mathrm{DO}}$-choke reactance (phase) for the first harmonic, in $\Omega$; and $R_{\mathrm{DO}}$-choke resistance (phase) for the first harmonic, in $\Omega$.

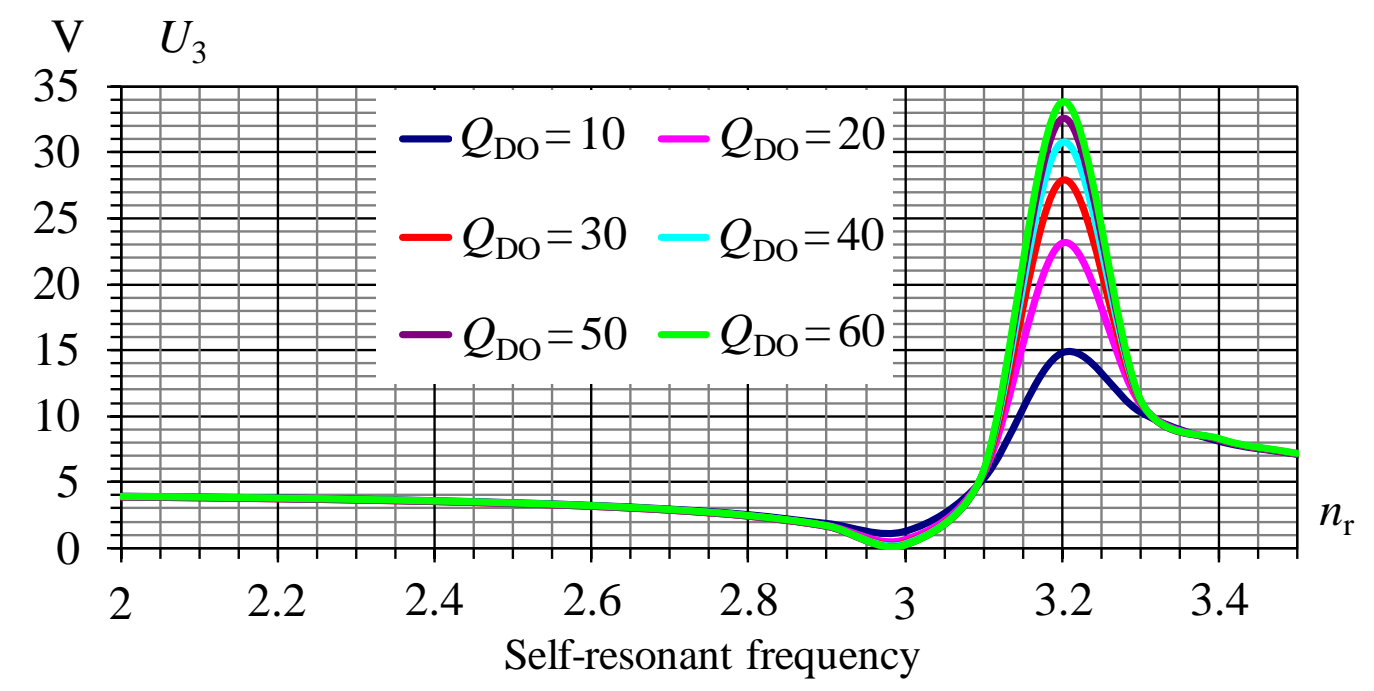

Figure 4. RMS value of third harmonic voltage in the transmission system as a function of the self-resonant frequency at different values of the choke $Q_{\mathrm{DO}}$-factor.

The resonant frequency $n_{\mathrm{r}}$ should be lower than 3 if the LC-type filters are designed for reducing the third, fourth, fifth, and successive harmonics. In view of the manufacturing tolerance (choke and capacitors) and aging of the system components, the filter was detuned and $n_{\mathrm{r}}=2.95$ was applied. Phase reactance of the capacitor bank was determined with the use of the below formula:

$$
X_{\mathrm{C}}=\frac{U_{\mathrm{NS}}^{2}}{Q_{\mathrm{Cr}} \cdot\left(1-\frac{1}{n_{\mathrm{r}}^{2}}\right)^{\prime}}
$$


where $U_{\mathrm{NS}}$-represents the network rated voltage, the RMS value of the interphase voltage of the first harmonic; and $Q_{\mathrm{Cr}}$-reactive power of the first harmonic injected into the system by the filter.

Capacitive reactance of the bank was used to calculate the first harmonic voltage $U_{C 1}$ on the bank terminal:

$$
U_{\mathrm{C} 1}=\frac{U_{\mathrm{NS}}}{1-\frac{1}{n_{\mathrm{r}}^{2}}} .
$$

The rated voltage of capacitors should be higher than the first harmonic voltage due to the presence of higher harmonics. The RMS value of voltage on the bank terminal is the algebraic sum of the individual harmonic voltages [37,38]:

$$
U_{\mathrm{C}}=U_{\mathrm{C} 1}+\sum_{n=2}^{m} U_{\mathrm{C} n}
$$

where $U_{\mathrm{C}}-\mathrm{RMS}$ value of the voltage on the bank terminal; $U_{\mathrm{C} 1}-\mathrm{RMS}$ value of the $50 \mathrm{~Hz}$ first harmonic voltage on the bank terminal; $U_{\mathrm{C} n}-\mathrm{RMS}$ value of the $n$th harmonic voltage on the bank terminal; $n$-successive harmonic in the transmission system (second, third, fourth, fifth, etc.); and $m$-the number of higher harmonics in the transmission system.

The above prediction stems from the IEC 60871-1:2014 standard [37] and its European equivalents EN 60871-1:2014 (for capacitors with rated voltage above $1 \mathrm{kV}$ ) and IEC 60831-1:1996 [38], as well as its European equivalent EN 60831-1:1996 (for capacitors up to $1 \mathrm{kV}$ ). In the literature, the RMS value of voltage on the bank terminal is often confused with the RMS value of the transmission system voltage [13,21,39-42], which is defined as the geometric sum of the individual harmonics in accordance with standard EN 50160:1994 [43]. The rated voltage of a capacitor bank should closely correspond to the RMS value of the voltage on the bank terminal. To reduce costs, the difference between the installed reactive power and the reactive power of the first harmonic injected into the system should be minimized. The proportionality of the rated voltage to rated power of a capacitor bank is given by the following formula:

$$
Q_{\mathrm{CN}}=\frac{U_{\mathrm{CN}}^{2}}{X_{\mathrm{C}}}
$$

Choke reactance was calculated with the use of the following formula:

$$
X_{\mathrm{DO}}=\frac{X_{\mathrm{C}}}{n_{r}^{2}}
$$

\subsection{Selection of a C-Type Filter}

C-type filters should be selected after choosing the appropriate LC-type filters. The capacitive reactance of the auxiliary capacitor bank and the inductive reactance of the choke for the first harmonic are equal:

$$
X_{\mathrm{CP}}=X_{\mathrm{DO}},
$$

where $X_{C P}-$ represents the capacitive reactance of the auxiliary capacitor bank for the first harmonic; and $X_{\mathrm{DO}}$-inductive reactance of the choke for the first harmonic.

When the resistance of the choke, auxiliary capacitors, and current circuits (cables, terminals, etc.) is disregarded, equivalent impedance for the first harmonic approximates zero. The main capacitor bank is supplied with a rated voltage of the network powering the entire filter. The selected capacitor bank should inject actual reactive power, calculated based on the below formula, into the transmission system:

$$
X_{\mathrm{CG}}=\frac{U_{\mathrm{NS}}^{2}}{Q_{\mathrm{Cr}}}
$$

where $X_{\mathrm{CG}}$-represents the capacitive reactance of the main capacitor bank for the first harmonic. 
A C-type filter will have self-resonant frequency of

$$
n_{\mathrm{r}}=\sqrt{\frac{X_{\mathrm{CP}}+X_{\mathrm{CG}}}{X_{\mathrm{DO}}}}
$$

Formula (10) can be modified to calculate the value of $X_{\mathrm{CP}}$ or $X_{\mathrm{DO}}$ with the use of the below equation:

$$
X_{\mathrm{DO}}=X_{\mathrm{CP}}=\frac{X_{\mathrm{CG}}}{n_{\mathrm{r}}^{2}-1} .
$$

The most difficult task in the process of designing a C-type filter is the selection of the damping resistor $R_{\mathrm{T}}$, which should

- guarantee that the entire system, with a C-type filter only and with LC-filters, has an inductive character for higher harmonics and a capacitive character for the first harmonic (which was not taken into account in [21,42] as well as [35,44-49]);

- filter out higher harmonic currents and reduce higher harmonics voltages;

- compensate the reactive power of the first harmonic in view of the manufacturing tolerance and aging of components $R, L$, and $C$ [50];

- reduce overvoltage in a system with a C-type filter.

Based on the above dependencies, an algorithm was developed for selecting a C-type filter for the required higher harmonic after compensation. The algorithm is presented in a diagram in Figure 5, and additionally, the algorithm equations are given in Appendix A.

System parameters have to be specified in the first step of the proposed algorithm (Figure 5). Depending on the number of the applied filters, the parameters of the LC-type filters for eliminating higher harmonic components (higher than second) are selected in Steps 2 to 4 . In systems with three LC-type filters, the third, fourth, and fifth harmonics are calculated in three loops $(\mathrm{s}=3)$. The parameters of a C-type filter are set as beginning from Step 5. Parameters such as $X_{\mathrm{CG}}, X_{\mathrm{CP}}, X_{\mathrm{DO}}$, and $R_{\mathrm{DO}}$ are selected in Steps 5 and 6. In Step 8, the resistance $\left(R_{T}\right)$ is set to ensure that the equivalent reactance has a positive value $X_{\text {zas }}>0$ to prevent parallel resonance. The filtering system's ability to reduce a given harmonic to a desirable value is verified in Step 9. If the above requirement is not met, the self-resonant frequency of a C-type filter is increased, and Steps 6 to 9 are repeated. The resonant frequency should not exceed $n_{\mathrm{r}}=2$, and the manufacturing tolerance of a C-type filter should be taken into consideration. 


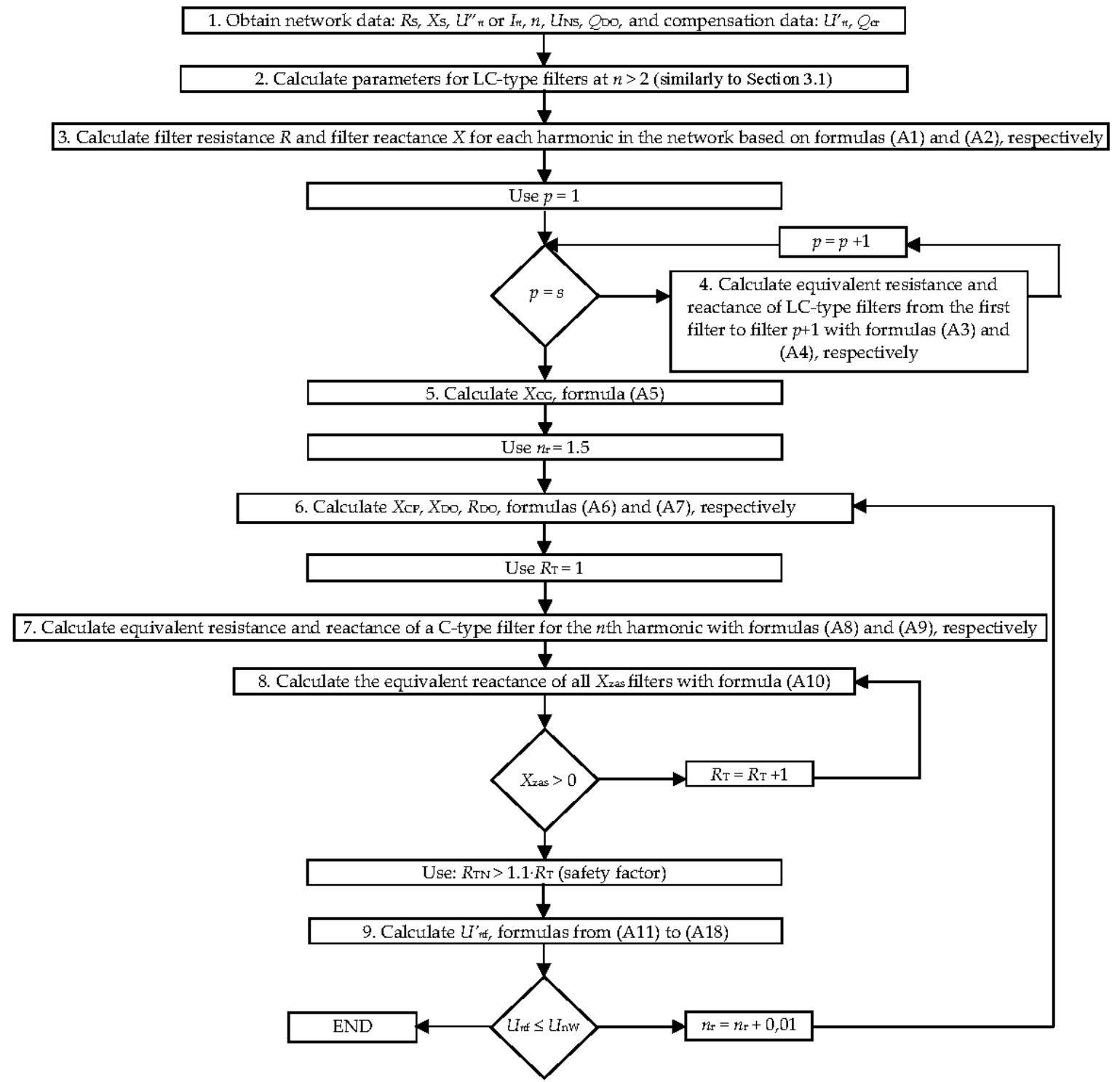

Figure 5. Algorithm steps for calculating the parameters of a C-type filter for the required $U_{n}{ }^{\prime}$ as in Equations (A1) to (A18) Appendix A.

\section{Simulation}

A number of computer simulations were run for the presented transmission system, including with the use of the proposed algorithm for selecting C-type filters. Different parameters of the transmission system and passive filters were used in the simulations. The choice of the damping resistor was the most important task. The parameters of an LC-type filter were selected first (Table 2), and they were used to analyze the operating requirements of a C-type filter. The highest self-resonant frequency that was possible in view of the manufacturing tolerance of the filter's elements was $n_{\mathrm{r}}=1.95$. The above value was adopted in Step 5 of the presented algorithm to maximally filtrate the second harmonic. The condition does not have to be verified after Step 9 (see Figure 5 and Appendix A). The main focus of the analysis was to select the parameters for resistor $R_{\mathrm{T}}$, which had been disregarded in the literature [35] or whose selection and influence on the filtering system had been presented incorrectly [21,46]. Resistor parameters have to ensure that the equivalent reactance of the second and third harmonic filters has an inductive character at the frequency of $100 \mathrm{~Hz}$ (Figure 6a). If inductive reactance is combined with an inductive transmission system, the result can be parallel resonance and a higher second harmonic in the transmission system. The results of the analysis indicate that resistor 
$R_{\mathrm{T}}$ should have minimum resistance of $236 \Omega$. If a fourth harmonic filter were incorporated into the system, resistance would equal $298 \Omega$ (Figure 6b). All system filters should be taken into account because the minimum resistance increases with the number of incorporated filters. Resistor $R_{\mathrm{T}}$ also discharges the second harmonic current in a C-type filter. Its resistance has to ensure that more than $90 \%$ of the active power of the second harmonic is discharged on the resistor and not on the other components (receivers and sources) of the transmission system (Figure 7).

Table 2. Parameters of the transmission system and the transformer.

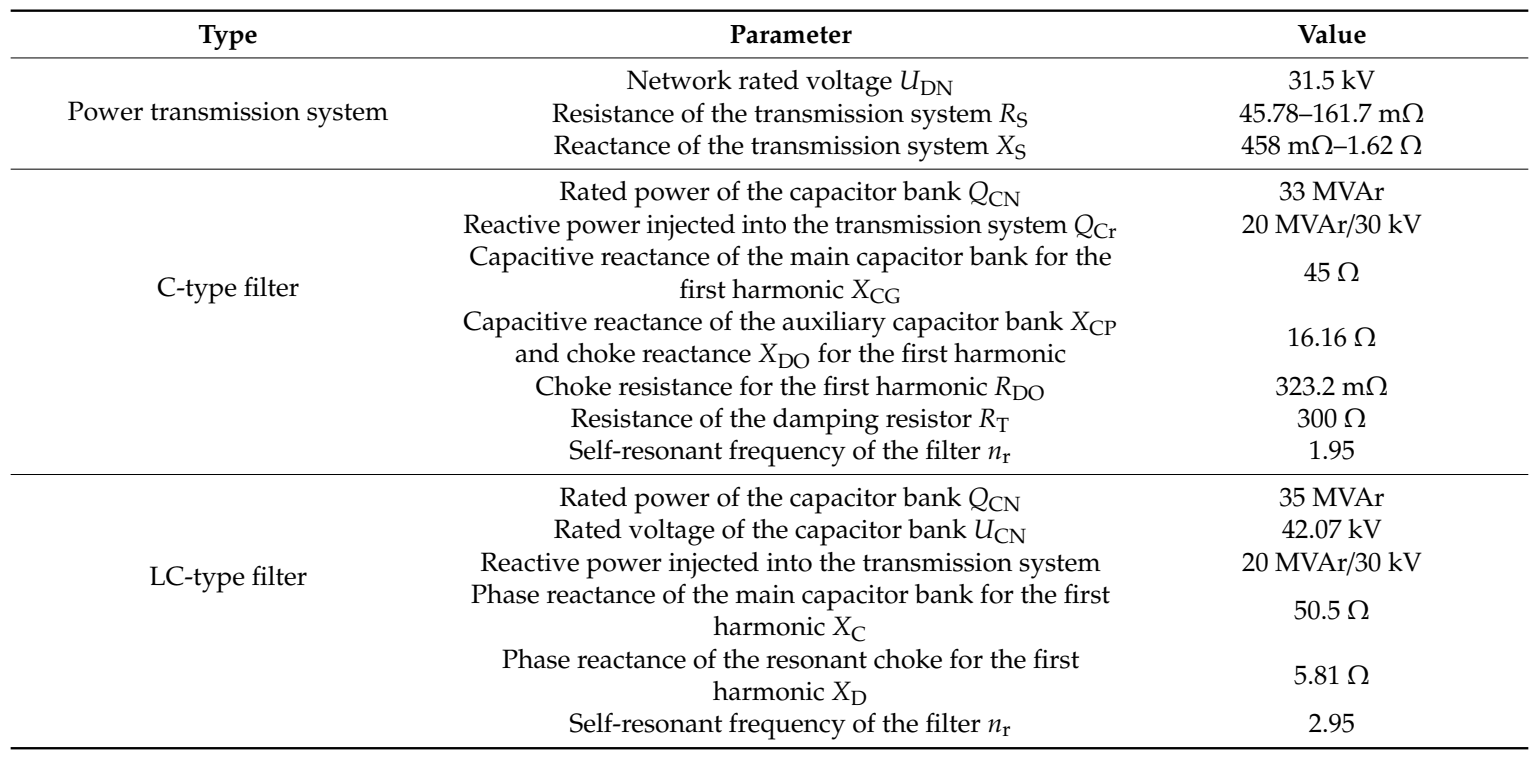

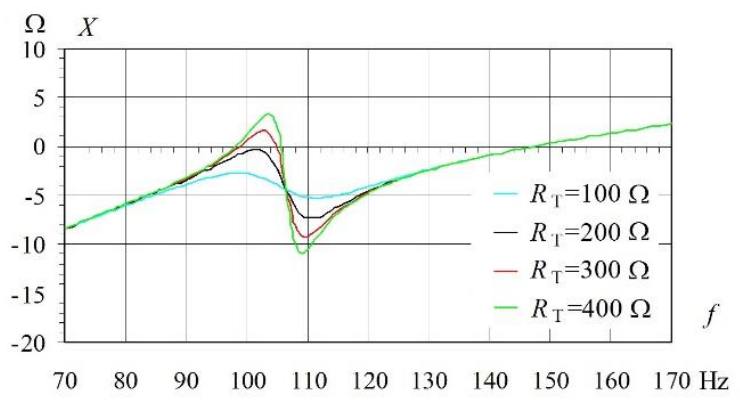

(a)

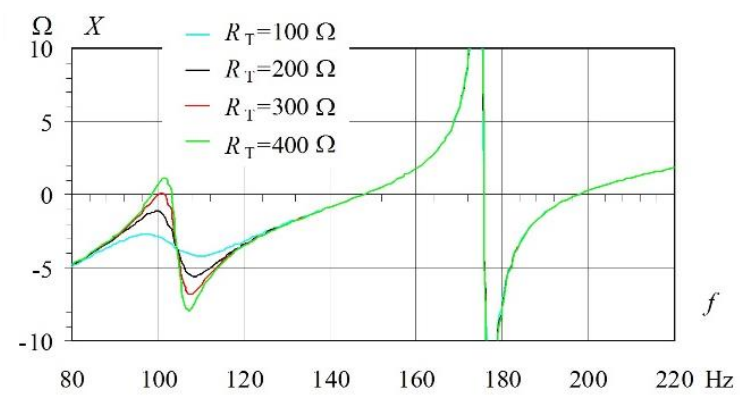

(b)

Figure 6. Equivalent reactance of the harmonic filters as a function of frequency at different resistance values of the damping resistor in a C-type filter. (a) Second and third filter. (b) Third and fourth filter. 


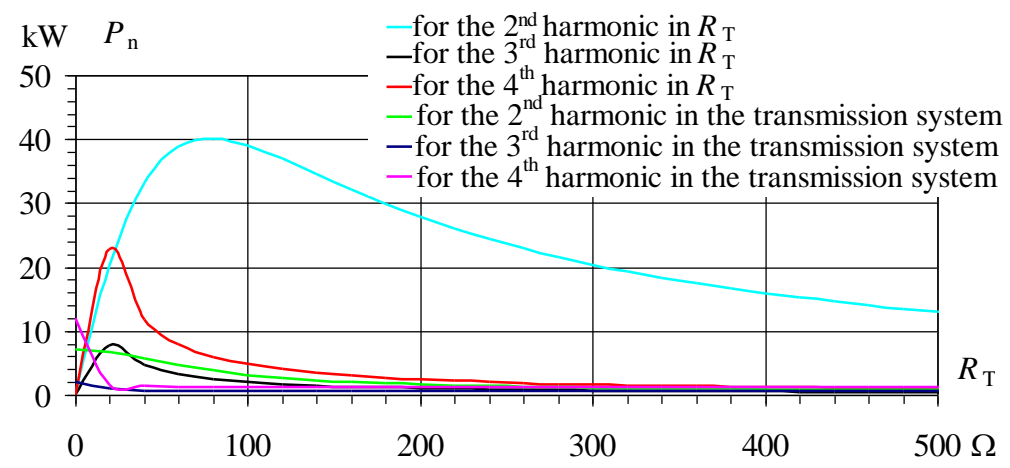

Figure 7. Active power of a higher harmonic discharged on the damping resistor $R_{\mathrm{T}}$ and in the transmission system as a function of the resistance of the damping resistor $R_{\mathrm{T}}$.

The compensation system can be expanded to include a fourth harmonic filter; therefore, a $300 \Omega$ damping resistor was used. The parameters of the C-type filter are presented in Table 2.

In practice, a C-type filter tuned to the third harmonic can be installed in two configurations:

- the capacitor bank is arranged in double-star connection (Figure 8a);

- the capacitor bank is arranged in an H-bridge (Figure 8b).

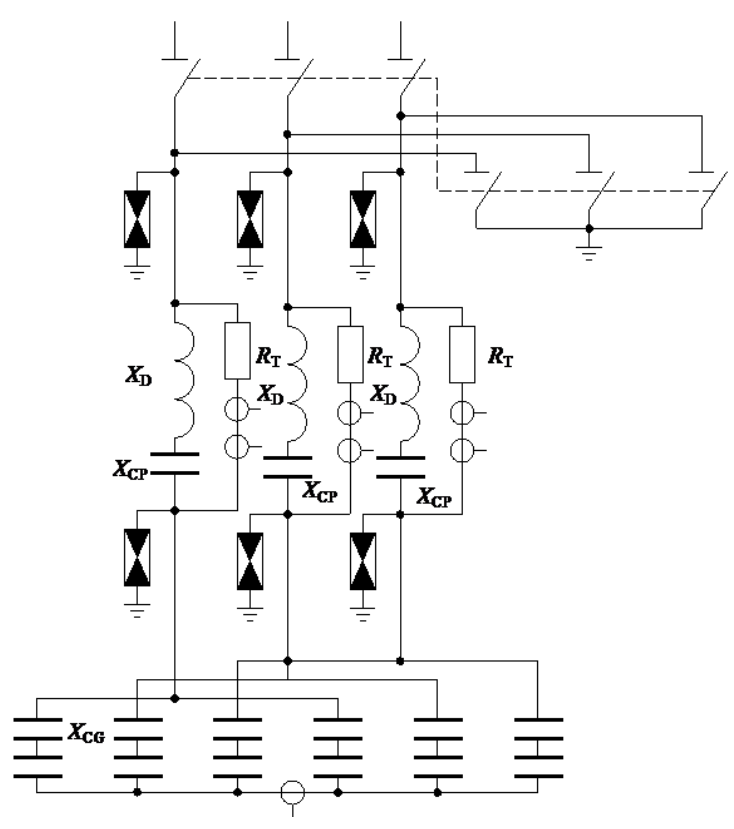

(a)

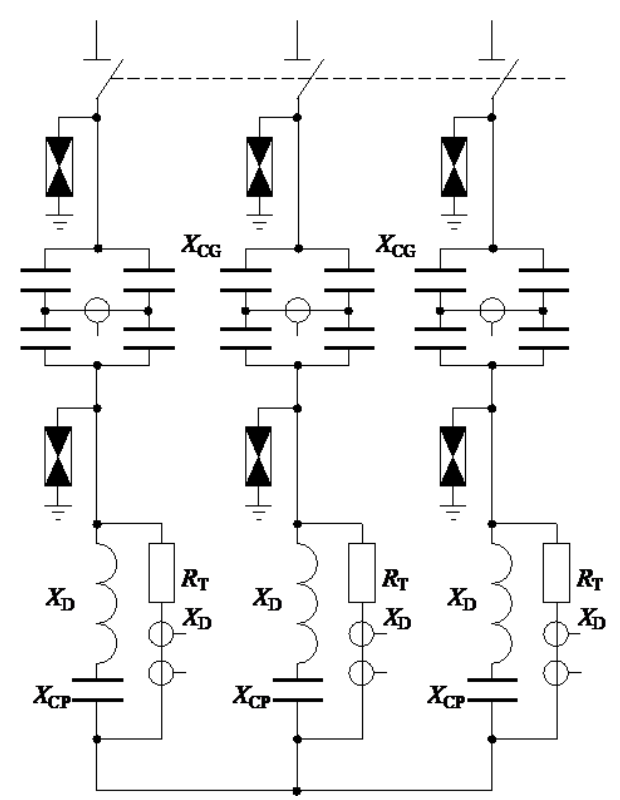

(b)

Figure 8. Active power of a higher harmonic discharged on the damping resistor $R_{\mathrm{T}}$ and in the transmission system as a function of the resistance of the damping resistor $R_{\mathrm{T}}$. (a) Double-star connection. (b) H-bridge.

The selection of a specific solution (Figure 8a,b) has significant implications for the overvoltage conditions of the compensation system. In a system where the capacitor bank is arranged in a double-star connection, when a short circuit occurs in the bank terminals, voltage will not be reduced to a safe level by surge protectors because

- for the periodic component of fault current $(50 \mathrm{~Hz})$, the reactance of the auxiliary bank with a resonant choke has practically zero value, which implies that the periodic component will flow through the auxiliary bank with the same magnitude that is noted during busbar overvoltage; 
- the flow of high fault current through the auxiliary bank causes very high voltage losses in different elements of the system $\left(X_{\mathrm{D}}, X_{\mathrm{CP}}\right)$; in the analyzed steel mill, overvoltage will exceed $300 \mathrm{kV}$.

When the bank is arranged in an H-bridge, a short circuit in the auxiliary bank will have a lower value than the current rating of the filter and compensator system. Effective protection for the auxiliary bank and the damping resistor poses an additional problem in both configurations. The required protection has to respond to the

- first harmonic in a $50 \mathrm{~Hz}$ system to protect the auxiliary bank;

- all harmonics to protect the damping resistor.

\section{Validating a Designed Filter in a Real-World System}

A system of filters (Figure 2b,c, Figures $8 a$ and $9 a, b$ ) was developed for the parameters presented in Table 2, and the higher harmonics $I_{\mathrm{n}}$ and $U_{\mathrm{n}}$ were measured. Measurements were conducted in the transformer field at $110 \mathrm{kV}$ (measuring point of the analyzed steel mill), and the results are presented in Figures 10 and 11. Measurements were carried out for two system configurations: with two parallel transformers T1 and T2 (Figure 2b), and with one transformer T3 (Figure 2c). Measurements were also performed when the higher harmonic filters were turned off in both configurations. The effectiveness of the C-type second harmonic filter and its influence on the transmission system were evaluated with the C-type filter turned off. The variations in the RMS values of the second, third, and fourth harmonic voltages during several operating cycles of an arc furnace are presented in Figure 11.

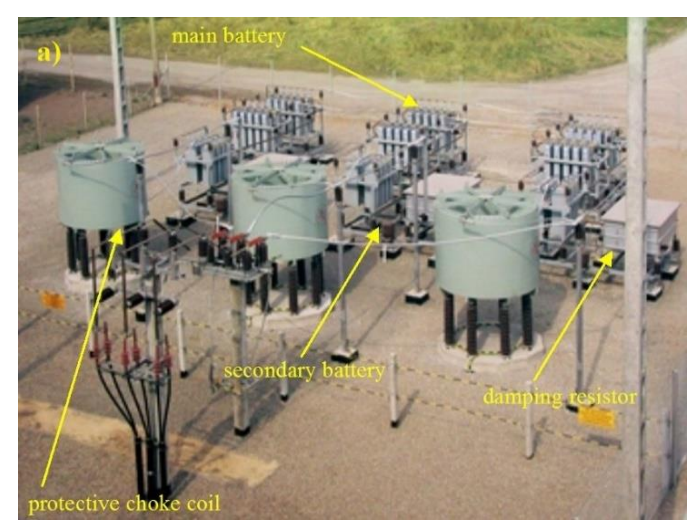

(a)

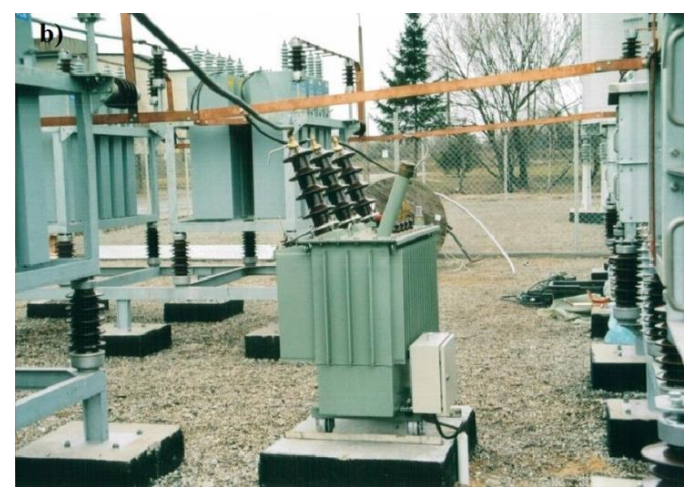

(b)

Figure 9. Real view of the designed system. (a) C-type filter. (b) $63 \mathrm{kVA} / 30 \mathrm{kV}$ transformer for fast discharge of the main capacitor bank of a C-type second harmonic filter. 


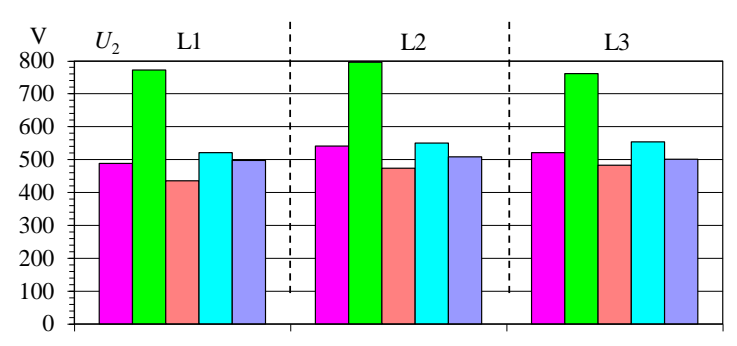

(a)

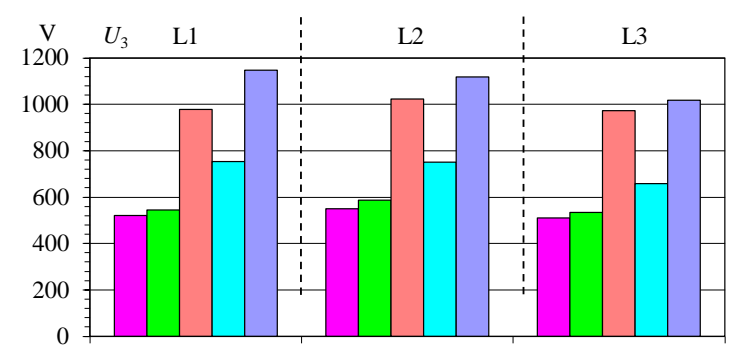

(c)

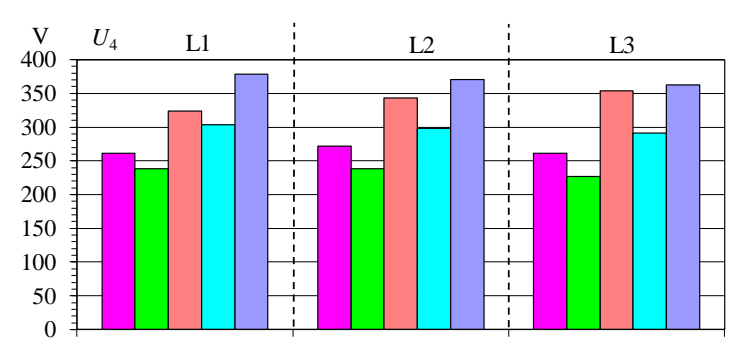

(e)

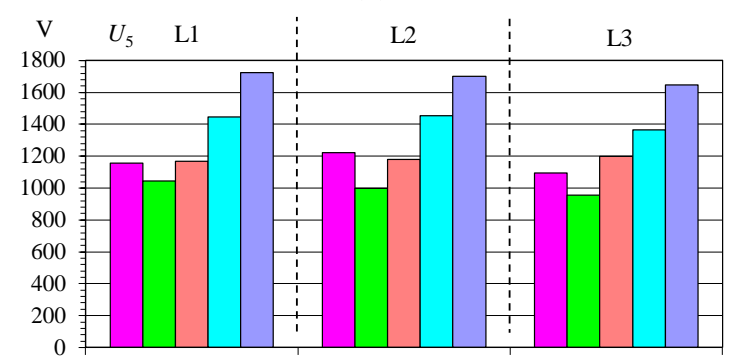

(g)

One transformer with a bank (Figure 2c)

One transformer with a third harmonic filter only (Figure 2c) $\square$ Two transformers with a bank (Figure 2b) One transformer without a bank (Figure 2c)

Figure 10. Arithmetic means of 500 maximum RMS values from all three phases. (a) Second harmonic voltages. (b) Second harmonic currents. (c) Third harmonic voltages. (d) Third harmonic currents. (e) Fourth harmonic voltages. (f) Fourth harmonic currents. (g) Fifth harmonic voltages. (h) Fifth harmonic currents.

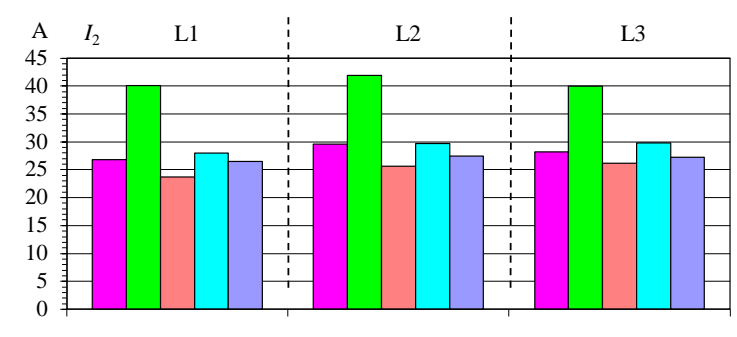

(b)

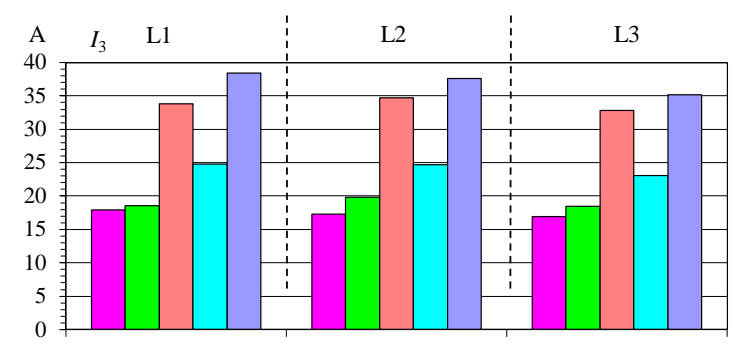

(d)

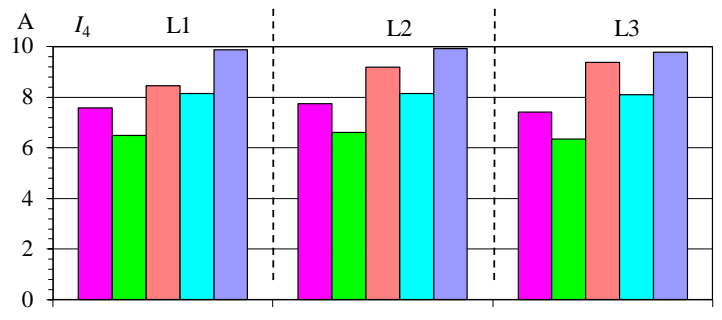

(f)

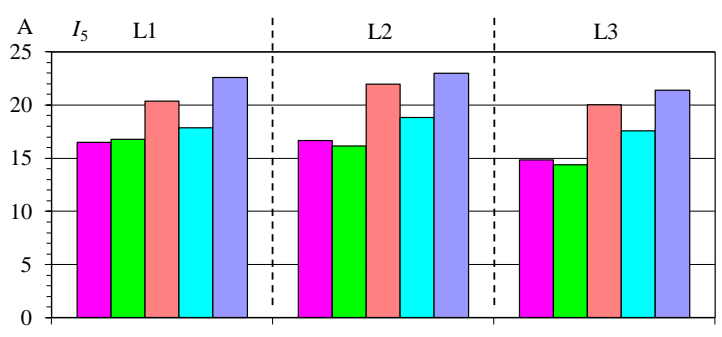

(h)

$\square$ Two transformers without a bank (Figure 2b) 
a) $\mathrm{V} \quad / / 2$

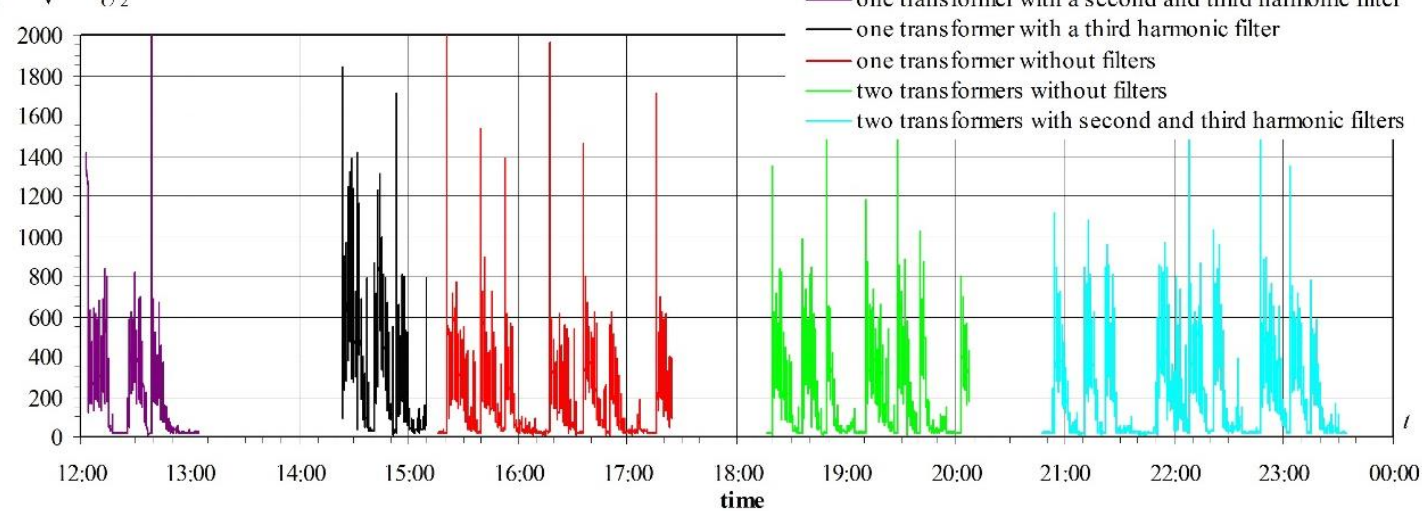

b) $\quad \mathrm{V} \quad \mathrm{U}_{3} \quad$ one transformer with a second and third harmonic filter

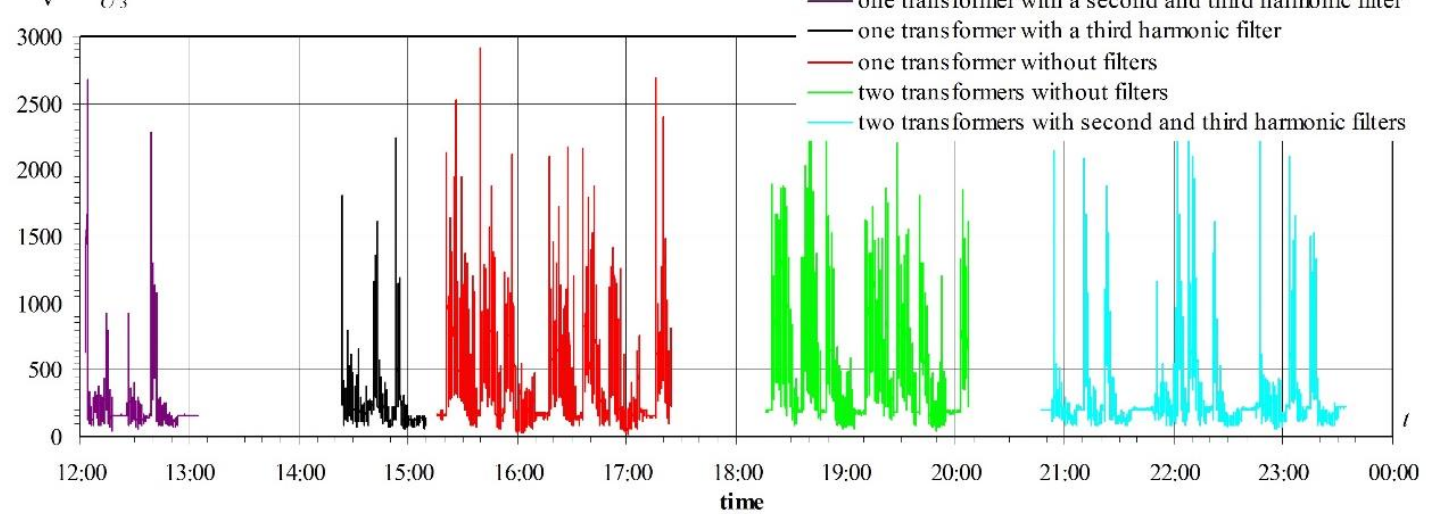

c) $\quad \mathrm{V} \quad U_{4}$

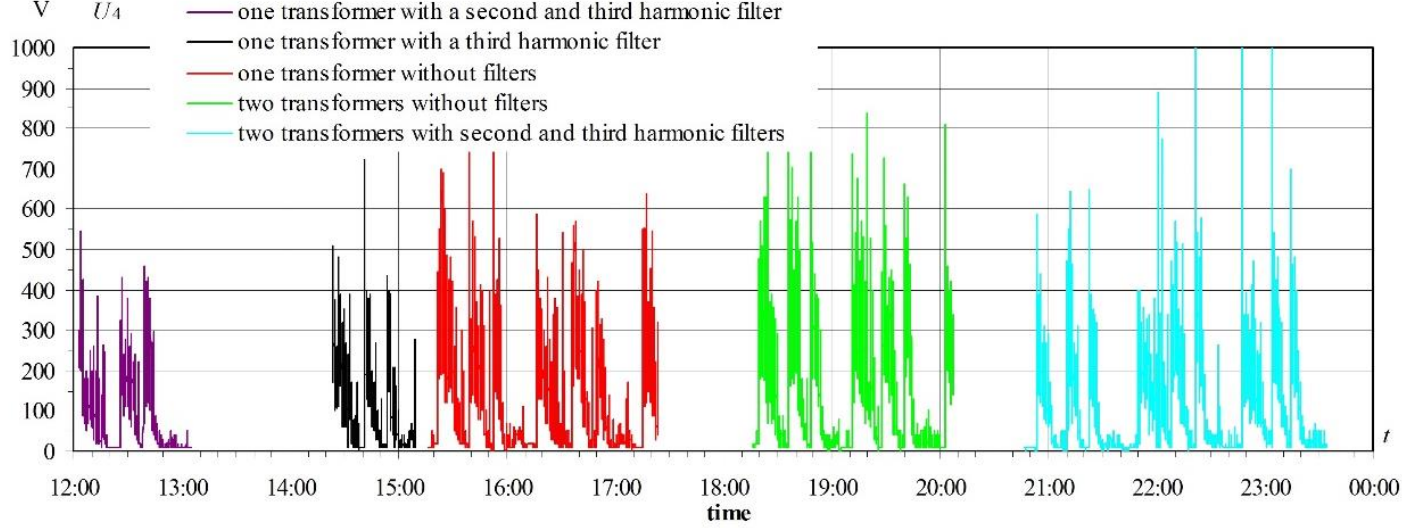

Figure 11. Variations in the RMS values in phase L1 in the transformer field on a $110 \mathrm{kV}$ busbar. (a) Second harmonic voltage. (b) Third harmonic voltage. (c) Fourth harmonic voltage.

\section{Conclusions}

The following conclusions can be formulated based on the computer simulations performed in this study:

- The effectiveness of a passive LC-type filter is strongly influenced by the degree to which the order of self-resonant frequency departs from the order of the filtered harmonic and from the order of the harmonic. Lower-order harmonics (third, fourth, and fifth) are significantly more influenced than the higher-order harmonics. In higher-order harmonics, the effectiveness of an LC-type filter will be reduced by only $10 \%$ when the value of $n_{\mathrm{r}}$ decreases from 11 to 10 . Therefore, a single filter can be used to eliminate two harmonics. For example, a filter with $n_{\mathrm{r}}=10.5$ will suppress the 11 th harmonic by around $95 \%$ and the 13th harmonic by $90 \%$ (Figure 3 ). 
- A filter's effectiveness is also influenced by choke resistance. However, this parameter has a negligent effect on filters where the order of self-resonant frequency considerably departs from the filtered harmonic. The protective choke influences a filter's effectiveness when the value of $n_{\mathrm{r}}$ approximates or exceeds the filtered harmonic, which could lead to parallel resonance $\left(n_{\mathrm{r}}=2.9-3.3\right.$ in Figure 4).

- The option of installing other higher-order filters in the system must be taken into account in the process of selecting the resistance $R_{\mathrm{T}}$ of a damping resistor in a C-type filter. In a system equipped with a C-type filter only, the minimum resistance of the damping resistor is $100 \Omega$. In a system equipped with a C-type filter and a third-order LC-type filter, the minimum resistance of the damping resistor is $236 \Omega$ (Figure 6a). The minimum resistance of the damping resistor increases to $298 \Omega$ when a fourth-order LC-type filter is installed in the system (Figure 6b). In this study, the resistance of the damping resistor was set at $R_{\mathrm{T}}=300 \Omega$.

- The true power generated by a damping resistor peaks at $40 \mathrm{~kW}$ for the second harmonic when resistance approximates $80 \Omega$. The true power generated by the resistor and the transmission system decreases at higher resistance values (Figure 7).

- In practice, a C-type filter can be installed in two configurations: a double-star connection (Figure 8a) or an H-bridge (Figure 8b). In this study, a double-star configuration was selected due to the ease of detecting short circuits in systems with a C-type filter.

The results of the analysis performed in a real-world system equipped with C-type passive filters for second harmonic generation and LC-type passive filters for third harmonic generation revealed the following:

- The activation of C-type and LC-type filters increased the RMS value of the second harmonic current injected into the transmission system by $10.8 \%$ when one transformer was used and by $7.2 \%$ when two transformers were used (Figure 10b), which increased the RMS value of higher harmonic voltage on the $110 \mathrm{kV}$ busbars (Figures 10a and 11a) by $10.1 \%$ when one transformer was used and by $7.1 \%$ when two transformers were used.

- The absence of a C-type filter for compensating second harmonic generation and the activation of only one LC-type filter for compensating third and higher harmonic generation increased the RMS value of second harmonic current injected into the transmission system by $62 \%$ (Figure 10a). The absence of a second harmonic filter increased the RMS value of second harmonic voltage by $68 \%$ (Figures 10a and 11a), which indicates that a C-type filter should be used for compensating harmonic generation in arc furnaces.

- The increase in equivalent impedance between an arc furnace and a measuring point resulting from a reduction in the number of transformers (from two to one) decreased the RMS value of second harmonic current injected into the transmission system by $7.1 \%$ when the capacitor bank was turned off and by $3.4 \%$ when the capacitor bank was turned on (Figure 10b). The above decreased the RMS value of second harmonic voltage by $7.6 \%$ when the capacitor bank was turned off and by $4.6 \%$ when the capacitor bank was turned on (Figure 10a).

- The activation of higher harmonic filters decreased the RMS value of third harmonic current by $94 \%$ when one transformer was used and by $53 \%$ when two transformers were used (Figure 10d). The RMS value of higher harmonic voltage on $110 \mathrm{kV}$ busbars decreased by $88 \%$ and $52 \%$, respectively (Figures 10c and 11b).

- A single transformer should be used instead of two parallel transformers with similar power. The above solution increases impedance on the $110 \mathrm{kV}$ side and decreases the RMS value of the third harmonic injected into the transmission system by $8.8 \%$ when the capacitor bank is turned off and by $28 \%$ when the capacitor bank is activated (Figure 10d). Lower generation of third harmonic current decreases the RMS value of third harmonic voltage on $110 \mathrm{kV}$ busbars by $9.1 \%$ and $27 \%$, respectively (Figure 10c). 
- The application of a C-type filter only for the second harmonic decreases the RMS value of the third harmonic current injected into the transmission system by $43.8 \%$ and decreases the RMS value of third harmonic voltage by $44 \%$ on $110 \mathrm{kV}$ busbars.

- The use of only one transformer instead of two also decreases the RMS value of fourth and fifth harmonic voltages and currents injected into the transmission system (Figures 10e-h and 11c).

- When the second and third harmonic filter is replaced with the third harmonic filter only, the RMS values of the second and third harmonic currents and voltages are decreased, which results from a drop in the equivalent impedance of the filters for harmonics higher than the third harmonic (Figure 10e-h).

Author Contributions: Formal analysis, A.G.L. and G.R.; methodology, investigation, software, and visualization, A.G.L.; calculation, A.G.L.; project administration and supervision, G.R.; writing-original draft, A.G.L.; writing-review and editing, A.G.L. and G.R. All authors have read and agreed to the published version of the manuscript.

Funding: This research received no external funding.

Conflicts of Interest: The authors declare no conflict of interest.

\section{Abbreviation}

$R_{\mathrm{Sn}} \quad$ transmission system resistance (phase): in $\Omega$

$X_{S n} \quad$ transmission system reactance (phase) for the $n$th harmonic, in $\Omega$

$X_{\mathrm{CG}} \quad$ reactance (phase) of the main capacitor bank for the first harmonic, in $\Omega$

$X_{\mathrm{CP}} \quad$ reactance (phase) of the auxiliary capacitor bank for the first harmonic, in $\Omega$

$X_{\mathrm{DO}} \quad$ choke reactance (phase) for the first harmonic, in $\Omega$

$I_{n} \quad n$th harmonic current, in A

$R_{\mathrm{DO}} \quad$ choke resistance (phase) for the first harmonic, in $\Omega$

$R_{\mathrm{T}} \quad$ resistance (phase) of the damping resistor for the first harmonic, in $\Omega$

$R_{\mathrm{f} p} \quad$ resistance (phase) of the $p$ th LC-type filter for the $n$th harmonic, in $\Omega$

$X_{\mathrm{f} n p} \quad$ reactance (phase) of the $p$ th LC-type filter for the $n$th harmonic, in $\Omega$

$R_{\text {zas } n(1, p+1)} \quad$ equivalent resistance (phase) of the first to the $p$ th LC-type filter for the $n$th harmonic, in $\Omega$

$X_{\text {zas } n(1, p+1)} \quad$ equivalent reactance (phase) of the first to the $p$ th LC-type filter for the $n$th harmonic, in $\Omega$

$R_{\mathrm{LC} n}$

$X_{\mathrm{LC} n}$

$R_{\mathrm{C} n}$ equivalent resistance of all LC-type filters (phase) for the $n$th harmonic, in $\Omega$

equivalent reactance all LC-type filters (phase) for the $n$th harmonic, in $\Omega$

equivalent resistance of a C-type filter (phase) for the $n$th harmonic, in $\Omega$

$X_{\mathrm{C} n}$

$R_{\text {zas }}$

$X_{\text {zas }}$ equivalent reactance of a C-type filter (phase) for the $n$th harmonic, in $\Omega$ equivalent resistance of all filters (phase) for the $n$th harmonic, in $\Omega$ equivalent reactance of all filters (phase) for the $n$th harmonic, in $\Omega$ actual reactive power supplied to the system, in VAr

$Q_{\mathrm{Cr}}$ $n$

\section{Appendix A}

Formulas for individual steps, presented in Figure 5:

Step 2:

Use the algorithm for a tuned harmonic filter designed in Section 3.1 and Equations (1) to (6).

Step 3:

Resistance (phase) of the $p$ th LC-type filter for the $n$th harmonic:

$$
R_{\mathrm{f} p}=R_{\mathrm{DO} p}
$$


Reactance (phase) of the $p$ th LC-type filter for the $n$th harmonic:

$$
X_{\mathrm{f} n p}=n X_{\mathrm{DO} p}-\frac{X_{\mathrm{C} p}}{n} .
$$

Step 4:

Equivalent resistance of two filters for the $n$th harmonic:

$$
R_{\text {zas } n(1, p+1)}=\frac{R_{n(1, p)}\left(R_{n(p+1)}^{2}+X_{n(p+1)}^{2}\right)+R_{n(p+1)}\left(R_{n(1, p)}^{2}+X_{n(1, p)}^{2}\right)}{\left(R_{n(1, p)}+R_{n(p+1)}\right)^{2}+\left(X_{n(1, p)}+X_{n(p+1)}\right)^{2}} .
$$

Equivalent reactance of two filters for the $n$th harmonic:

$$
X_{\text {zas } n(1, p+1)}=\frac{X_{n(1, p)}\left(R_{n(p+1)}^{2}+X_{n(p+1)}^{2}\right)+X_{n(p+1)}\left(R_{n(1, p)}^{2}+X_{n(1, p)}^{2}\right)}{\left(R_{n(1, p)}+R_{n(p+1)}\right)^{2}+\left(X_{n(1, p)}+X_{n(p+1)}\right)^{2}} .
$$

Step 5:

Reactance (phase) of the main capacitor bank for the first harmonic a C-type filter:

$$
X_{\mathrm{CG}}=\frac{U_{\mathrm{NS}}^{2}}{Q_{\mathrm{Cr}}} .
$$

Steps 6:

Choke reactance (phase) for the first harmonic a C-type filter:

$$
X_{\mathrm{DO}}=X_{\mathrm{CP}}=\frac{X_{\mathrm{CG}}}{n_{\mathrm{r}}^{2}-1} .
$$

Choke resistance (phase) for the first harmonic a C-type filter:

$$
R_{\mathrm{DO}}=\frac{X_{\mathrm{DO}}}{Q_{\mathrm{DO}}}
$$

Steps 7:

Equivalent resistance of a C-type filter for the $n$th harmonic:

$$
R_{\mathrm{C} n}=\frac{R_{\mathrm{T}} \cdot\left\{R_{\mathrm{DO}} \cdot R_{\mathrm{T}}+\left[R_{\mathrm{DO}}^{2}+\left(n X_{\mathrm{DO}}-\frac{X_{\mathrm{CP}}}{n}\right)^{2}\right]\right\}}{\left(R_{\mathrm{DO}}+R_{\mathrm{T}}\right)^{2}+\left(n X_{\mathrm{DO}}-\frac{X_{\mathrm{CP}}}{n}\right)^{2}} .
$$

Equivalent reactance of a C-type filter for the $n$th harmonic:

$$
X_{\mathrm{C} n}=\frac{R_{\mathrm{T}}^{2} \cdot\left(n X_{\mathrm{DO}}-\frac{X_{\mathrm{CP}}}{n}\right)}{\left(R_{\mathrm{DO}}+R_{\mathrm{T}}\right)^{2}+\left(n X_{\mathrm{DO}}-\frac{X_{\mathrm{CP}}}{n}\right)^{2}}-\frac{X_{\mathrm{CG}}}{n} .
$$

Steps 8:

Equivalent reactance of filters for the $n$th harmonic (for $n=2$ ):

$$
X_{\mathrm{zas}}=\frac{X_{\mathrm{LC} n}\left(R_{\mathrm{C} n}^{2}+X_{\mathrm{C} n}^{2}\right)+X_{\mathrm{C} n}\left(R_{\mathrm{LC} n}^{2}+X_{\mathrm{LC} n}^{2}\right)}{\left(R_{\mathrm{LC} n}+R_{\mathrm{C} n}\right)^{2}+\left(X_{\mathrm{LC} n}+X_{\mathrm{C} n}\right)^{2}} .
$$

Steps 9:

$$
R_{\mathrm{C} n}=\frac{R_{\mathrm{TN}} \cdot\left\{R_{\mathrm{DO}} \cdot R_{\mathrm{TN}}+\left[R_{\mathrm{DO}}^{2}+\left(n \mathrm{X}_{\mathrm{DO}}-\frac{X_{\mathrm{CP}}}{n}\right)^{2}\right]\right\}}{\left(R_{\mathrm{DO}}+R_{\mathrm{TN}}\right)^{2}+\left(n X_{\mathrm{DO}}-\frac{X_{\mathrm{CP}}}{n}\right)^{2}} .
$$


Equivalent reactance of a C-type filter for the $n$th harmonic:

$$
X_{\mathrm{C} n}=\frac{R_{\mathrm{TN}}^{2} \cdot\left(n X_{\mathrm{DO}}-\frac{X_{\mathrm{CP}}}{n}\right)}{\left(R_{\mathrm{DO}}+R_{\mathrm{TN}}\right)^{2}+\left(n X_{\mathrm{DO}}-\frac{X_{\mathrm{CP}}}{n}\right)^{2}}-\frac{X_{\mathrm{CG}}}{n} .
$$

Equivalent resistance of filters for the $n$th harmonic:

$$
R_{\mathrm{zas}}=\frac{R_{\mathrm{LC} n}\left(R_{\mathrm{C} n}^{2}+\mathrm{X}_{\mathrm{C} n}^{2}\right)+R_{\mathrm{C} n}\left(R_{\mathrm{LC} n}^{2}+X_{\mathrm{LC} n}^{2}\right)}{\left(R_{\mathrm{LC} n}+R_{\mathrm{C} n}\right)^{2}+\left(X_{\mathrm{LC} n}+X_{\mathrm{C} n}\right)^{2}} .
$$

Equivalent reactance of filters for the $n$th harmonic:

$$
X_{\mathrm{zas}}=\frac{X_{\mathrm{LC} n}\left(R_{\mathrm{C} n}^{2}+X_{\mathrm{C} n}^{2}\right)+X_{\mathrm{C} n}\left(R_{\mathrm{LC} n}^{2}+X_{\mathrm{LC} n}^{2}\right)}{\left(R_{\mathrm{LC} n}+R_{\mathrm{C} n}\right)^{2}+\left(X_{\mathrm{LC} n}+X_{\mathrm{C} n}\right)^{2}} .
$$

Equivalent resistance of the transmission system for the $n$th harmonic:

$$
R_{\mathrm{z} n}=\frac{R_{\mathrm{S} n}\left(R_{\mathrm{f} n}^{2}+X_{\mathrm{f} n}^{2}\right)+R_{\mathrm{f} n}\left(R_{\mathrm{S} n}^{2}+X_{\mathrm{S} n}^{2}\right)}{\left(R_{\mathrm{S} n}+R_{\mathrm{S} n}\right)^{2}+\left(X_{\mathrm{S} n}+X_{\mathrm{f} n}\right)^{2}} .
$$

Equivalent reactance of the transmission system for the $n$th harmonic:

$$
X_{\mathrm{z} n}=\frac{X_{\mathrm{S} n}\left(R_{\mathrm{f} n}^{2}+X_{\mathrm{f} n}^{2}\right)+X_{\mathrm{f} n}\left(R_{\mathrm{S} n}^{2}+X_{\mathrm{S} n}^{2}\right)}{\left(R_{\mathrm{S} n}+R_{\mathrm{S} n}\right)^{2}+\left(X_{\mathrm{S} n}+X_{\mathrm{f} n}\right)^{2}} .
$$

Phase voltage of the $n$th harmonic after compensation with $k$ capacitor unit:

$$
U_{n \mathrm{f}}^{\prime}=\sqrt{R_{\mathrm{z} n}^{2}+X_{\mathrm{z} n}^{2}} \cdot I_{n}
$$

Interphase voltage of the $n$th harmonic after compensation with $k$ capacitor bank:

$$
U_{n \mathrm{mf}}^{\prime}=\sqrt{3} \cdot \sqrt{R_{\mathrm{z} n}^{2}+X_{\mathrm{z} n}^{2}} \cdot I_{n}
$$

\section{References}

1. Alcalá, J.; Cárdenas, V.; Aganza, A.; Gudiño-Lau, J.; Charre, S. The Performance of the BTB-VSC for Active Power Balancing, Reactive Power Compensation and Current Harmonic Filtering in the Interconnected Systems. Energies 2020, 13, 831. [CrossRef]

2. Ivry, P.M.; Oke, O.A.; Thomas, D.W.P.; Sumner, M. Predicting Harmonic Distortion of Multiple Converters in a Power System. J. Electr. Comput. Eng. 2017, 2017, 7621413. [CrossRef]

3. Lange, A.; Pasko, M. Reducing energy consumption in production processes and parameters describing the quality of electrical energy. Przeglad Elektrotech. 2020, 96, 17-20. [CrossRef]

4. Lange, A.; Pasko, M. The impact of the work of modern welding equipment on quality and energy consumption. Przeglad Elektrotech. 2017, 93, 152-155.

5. Czapp, S.; Borowski, K. Immunity of residual current devices to the impulse leakage current in circuits with variable speed drives. Elektron. Ir Elektrotech. 2013, 19, 15-18. [CrossRef]

6. Czapp, S.; Dobrzyński, K.; Klucznik, J.; Lubośny, Z.; Kowalak, R. Improving sensitivity of residual current transformers to high frequency earth fault currents. Arch. Electr. Eng. 2017, 66, 485-494. [CrossRef]

7. Czapp, S.; Guzinski, J. Electric shock hazard in circuits with variable-speed drives. Bull. Pol. Acad. Sci. Tech. Sci. 2018, 66, 361-372.

8. Redlarski, G. Predicting the phase difference in the parallel connection of electrical engineering systems. Przeglad Elektrotech. 2012, 88, 260-262. 
9. Żak, A.; Krawczuk, M.; Redlarski, G.; Doliński, Ł.; Koziel, S. A three-dimensional periodic beam for vibroacoustic isolation purposes. Mech. Syst. Signal Process. 2019, 130, 524-544. [CrossRef]

10. Deilami, S.; Muyeen, S.M. An Insight into Practical Solutions for Electric Vehicle Charging in Smart Grid. Energies 2020, 13, 1545. [CrossRef]

11. Jaworski, J.; Redlarski, G. A compartment model of alveolar-capillary oxygen diffusion with ventilation-perfusion gradient and dynamics of air transport through the respiratory tract. Comput. Biol. Med. 2014, 51, 159-170. [CrossRef] [PubMed]

12. Palkowski, A.; Redlarski, G. Basic Hand Gestures Classification Based on Surface Electromyography. Comput. Math. Methods Med. 2016, 2016, 6481282. [CrossRef] [PubMed]

13. Chang, G.W.; Chu, S.Y.; Wang, H.L. A new method of passive harmonic filter planning for controlling voltage distortion in a power system. IEEE Trans. Power Deliv. 2006, 21, 305-312. [CrossRef]

14. Gała, M.; Jagieła, K.; Guła, R. The influence of the induction furnaces operation on the voltage distortion in low voltage network. Przeglad Elektrotech. 2006, 82, 127-129.

15. Jagieła, K.; Gała, M. Electrical Power Engineering Parameters for Characterizing the Work of the Electric Arc Furnace for Melting Scrap Steel. In Proceedings of the XII International Conference on Science and Technology Production and management in metallurgy, Ustroń Jaszowiec, Poland, 5-7 July 2004; pp. 109-112.

16. Kuśmierek, Z. Harmonics in the Power Systems. Przeglad Elektrotech. 2006, 82, 8-19.

17. Pasko, M.; Lange, A. Influence of arc and induction furnaces on the electric energy quality and possibilities of its improvement. Przeglad Elektrotech. 2009, 85, 67-74.

18. Wciślik, M. Characteristics of the symmetrical circuit of arc furnace in steady state during the melting. Przeglad Elektrotech. 2011, 87, 68-71.

19. Lange, A.; Pasko, M. Compensation of the reactive power and filtration of high harmonics by means of passive LC filters. Przeglad Elektrotech. 2010, 86, 126-129.

20. Benysek, G.; Pasko, M. Power Theories for Improved Power Quality. In Book Power Systems; Springer: London, UK, 2012; pp. 1-214.

21. Abdel Aleem, S.H.E.; Zobaa, A.F.; Abdel Aziz, M.M. Optimal C-Type Passive Filter Based on Minimization of the Voltage Harmonic Distortion for Nonlinear Loads. IEEE Trans. Ind. Electron. 2012, 59, 281-289. [CrossRef]

22. Zobaa, A.F. Voltage Harmonic Reduction for Randomly Time-Varying Source Characteristics and Voltage Harmonics. IEEE Trans. Power Deliv. 2006, 21, 816-822. [CrossRef]

23. Limongi, L.R.; Bradaschia, F.; de Oliveira Lima, C.H.; Cavalcanti, M.C. Reactive Power and Current Harmonic Control Using a Dual Hybrid Power Filter for Unbalanced Non-Linear Loads. Energies 2018, 11, 1392. [CrossRef]

24. Kececioglu, O.F.; Acikgoz, H.; Sekkeli, M. Advanced configuration of hybrid passive filter for reactive power and harmonic compensation. SpringerPlus 2016, 5, 1228. [CrossRef] [PubMed]

25. Syed Nasir, S.N.; Jamian, J.J.; Mustafa, M.W. Minimizing Harmonic Distortion Impact at Distribution System with Considering Large-Scale EV Load Behaviour Using Modified Lightning Search Algorithm and Pareto-Fuzzy Approach. Complexity 2018, 2018, 6587493. [CrossRef]

26. Zhao, Z.-Y.; Chen, C.-H.; Bao, S.-X.; Fang, T.-X.; Wang, X.-H. Application of TCR-Type SVC in Power Substation and Electric Arc Furnaces. In Proceedings of the Conference IEEE PES T\&D 2010, New Orleans, LA, USA, 19-22 April 2010.

27. Samet, H.; Parniani, M. Predictive Method for Improving SVC Speed in Electric Arc Furnace Compensation. IEEE Trans. Power Deliv. 2007, 22, 732-734. [CrossRef]

28. Hamedani Golshan, M.E.; Samet, H. Updating Stochastic Models of Arc Furnace Reactive Power by Genetic Algorithm. In Proceedings of the 14th International Conference on Harmonics and Quality of Power-ICHQP, Bergamo, Italy, 26-29 September 2010.

29. Zamani, M.A.; Moghaddasian, M.; Joorabian, M.; Seifossadat, S.G.; Yazdani, A. C-Type Filter Design Based on Power-Factor Correction for 12-Pulse HVDC. In Proceedings of the 34th Annual Conference of IEEE Industrial Electronics, Orlando, FL, USA, 10-13 November 2008.

30. Horton, R.; Dugan, R.; Hallmark, D. Novel Design Methodology for C-Type Harmonic Filter Banks Applied in HV and EHV Networks. In Proceedings of the Conference PES T\&D 2012, Orlando, FL, USA, 7-10 May 2012; pp. 1-6.

31. Zhang, G.; Wang, Y.Y.; Xu, W.; Sitther, E. Characteristic Parameter-Based Detuned C-Type Filter Design. IEEE Power Energy Technol. Syst. J. 2018, 5, 65-72. [CrossRef]

32. Lamlom, A.; Ahmed Ibrahim, A.; Balci, M.E.; Karadeniz, A.; Abdel Aleem, S.H.E. Optimal Design and Analysis of Anti-Resonance C-Type High-Pass Filters. In Proceedings of the IEEE International Conference 
on Environment and Electrical Engineering and 2017 IEEE Industrial and Commercial Power Systems Europe (EEEIC/I\&CPS Europe), Milan, Italy, 6-9 June 2017.

33. Habibolahzadeh, M.; Mahdinia Roudsari, H.; Jalilian, A.; Jamali, S. Improved Railway Static Power Conditioner Using C-Type Filter in Scott Co-Phase Traction Power Supply System. In Proceedings of the 10th International Power Electronics, Drive Systems and Technologies Conference (PEDSTC), Shiraz, Iran, 12-14 February 2019.

34. Wang, Y.; Xu, S.; Xu, W.; Xiao, X.; Wu, J. Comparative Studies on Design Methods for Detuned C-type Filter. IEEE Trans. Power Deliv. 2019, 1. [CrossRef]

35. Gerçek, C.Ö.; Ermis, M.; Ertas, A.; Köse, K.N.; Ünsar, Ö. Design, Implementation, and Operation of a New C-Type 2nd Harmonic Filter for Electric Arc and Ladle Furnaces. IEEE Trans. Ind. Appl. 2011, 47, 1545-1557. [CrossRef]

36. International Electrotechnical Commission (IEC). Industrial a.c. Networks Affected by Harmonics-Application of Filters and Shunt Capacitors (IEC 61642: 1997); IEC: Geneva, Switzerland, 1997.

37. International Electrotechnical Commission (IEC). Shunt Capacitors for a.c. Power Systems Having a Rated Voltage above 1000 V_Part 1: General (IEC 6081-1:2014); IEC: Geneva, Switzerland, 2014.

38. International Electrotechnical Commission (IEC). Shunt Power Capacitors of the Self-Healing Type for a.c. Systems Having a Rated Voltage up to and Including 1000 V-Part 1: General-Performance, Testing and Rating-Safety Requirements-Guide for Installation and Operation (IEC 60831-1:2014); IEC: Geneva, Switzerland, 2014.

39. Badrzadeh, B.; Smith, K.S.; Wilson, R.C. Designing Passive Harmonic Filters for an Aluminum Smelting Plant. IEEE Trans. Ind. Appl. 2011, 47, 973-983. [CrossRef]

40. Das, J.C. Passive filters-potentialities and limitations. IEEE Trans. Ind. Appl. 2004, 40, 232-241. [CrossRef]

41. Mohamed, I.F.; Abdel Aleem, S.H.; Ibrahim, A.M.; Zobaa, A.F. Optimal Sizing of C-Type Passive Filters under Non-Sinusoidal Conditions. Energy Technol. Policy 2014, 1, 35-44. [CrossRef]

42. Klempka, R.; Hanzelka, Z.; Yuri Varetsky, Y. Bank Harmonic Filters Operation in Power Supply System-Cases Studies. In Power Quality Issues; InTech Open: London, UK, 2013; Chapter 8; pp. 201-230.

43. International Electrotechnical Commission (IEC). Voltage Characteristics of Electricity Supplied by Public Distribution Systems (EN 50160:1994); IEC: Geneva, Switzerland, 1994.

44. Balci, M.E.; Karaoglan, A.D. Optimal Design of C-type Passive Filters Based on Response Surface Methodology for Typical Industrial Power Systems. Electr. Power Compon. Syst. 2013, 41, 653-668. [CrossRef]

45. Balci, M.E. Optimal C-Type Filter Design to Maximize Transformer's Loading Capability under Non-Sinusoidal Conditions. Electr. Power Compon. Syst. 2014, 42, 1565-1575. [CrossRef]

46. Dwyer, R.; Nguyen, H.V.; Ashmore, S.G. C filters for wide-bandwith harmonic attenuation with low losses. IEEE Power Eng. Soc. Winter Meet. Conf. Publ. 2000, 4, 2955-2960.

47. Klempka, R. A New Method for the C-Type Passive Filter Design. Przeglad Elektrotech. 2012, 88, $277-281$.

48. Kovernikova, L.I. Nguyen Chi Thanh, an Optimization Approach to Calculation of Passive Filter Parameters Based on Particle Swarm Optimization. In Proceedings of the International Conference on Renewable Energies and Power Quality (ICREPQ'12), Santiago de Compostela, Spain, 28-30 March 2012.

49. Nassif, A.B.; Xu, W.; Freitas, W. An investigation on the selection of filter topologies for passive filter applications. IEEE Trans. Power Deliv. 2009, 24, 1710-1718. [CrossRef]

50. Lin, K.P.; Lin, M.H.; Lin, T.P. An Advanced Computer Code for Single-Tuned Harmonic Filter Design. IEEE Trans. Ind. Appl. 1998, 34, 640-648.

(C) 2020 by the authors. Licensee MDPI, Basel, Switzerland. This article is an open access article distributed under the terms and conditions of the Creative Commons Attribution (CC BY) license (http://creativecommons.org/licenses/by/4.0/). 